\title{
Spatial clustering of twig-nesting ants corresponds with metacommunity assembly processes
}

\author{
GeORGe LivingSTON ${ }^{\bowtie, 1} \&$ Doug JACKSON ${ }^{2}$ \\ 1. Section of Integrative Biology, University of Texas at Austin, USA. 2. Department of Ecology and Evolutionary Biology, \\ University of Michigan-Ann Arbor, USA.
}

\begin{abstract}
Aвstract. The metacommunity concept and associated models are poorly integrated with the field of landscape ecology. One way to promote synthesis is to identify situations in which specific metacommunity models correspond to specific and explicit spatial patterns in the distribution of communities across space. We explore this possible link using mapped communities of twig-nesting ants on coffee plants from a plantation in southern Mexico. Previous work has shown species sorting to predominate among common species and mass effects among rare species. We test whether differential patterns of spatial clustering among dominant and subdominant ant species correspond to a species sorting and mass effects model, respectively. We find significant clustering among subdominant species in two of six sites and no clustering among dominants. At the species level, significant clustering was observed in $23 \%$ of cases. These results partially support our hypothesis and may be explained mechanistically by the interstitial hypothesis, whereby rare species persist in "gaps" among dominants. At the spatial scales we examined, we found no support for the ant-mosaic. Our results suggest further study linking metacommunity models to specific and explicit spatial patterns may yield insights on pattern and process relationships in landscapes.
\end{abstract}

[Keywords: spatial pattern, clustering, dispersal, twig-nesting ants, tropical agroecosystem, landscape]

\begin{abstract}
Resumen. Agrupación espacial de hormigas que anidan en cafetos corresponde con procesos de ensamblaje de la metacomunidad: El concepto de metacomunidad y sus modelos asociados están pobremente integrados en el campo de la ecología de paisaje. Una manera de promover una síntesis es identificar situaciones en donde modelos específicos de metacomunidad correspondan a patrones específicos y explícitos en la distribución de comunidades a través del espacio. Exploramos esta posible relación usando un mapeo de las comunidades de hormigas que anidan en cafetos en un agroecosistema de café en el sur de México. Trabajos previos han demostrado que el modelo de ordenamiento de especies predomina para especies comunes y el de efecto de masa para especies raras. Estudiamos si los patrones diferenciales de la agrupación espacial entre las especies dominantes y subdominantes corresponden a un modelo de ordenamiento de especies y de efecto de masa, respectivamente. Encontramos una agrupación significativa entre las especies subdominantes en dos de los seis sitios y no agrupación entre los dominantes. A nivel de especie, observamos una agrupación significativa en $23 \%$ de los casos. Estos resultados sustentan parcialmente nuestra hipótesis y pueden ser explicado mecánicamente por la hipótesis intersticial; por lo cual, las especies subdominantes persisten en 'aberturas' entre las especies dominantes. Al examinar a nuestro nivel de escala espacial, no encontramos sustento para la hipótesis de mosaico en hormigas. Nuestros resultados sugieren que más estudios vinculando a modelos de metacomunidad con patrones espaciales específicos y explícitos pueden aportar conocimientos sobre patrones y procesos relacionados en paisajes.
\end{abstract}

[Palabras clave: patrón espacial, agrupación, dispersión, hormigas que anidan en ramas, agroecosistema tropical, paisaje]

\section{INTRODUCTION}

Community ecology is undergoing a major transformation to multi-scale spatial approaches driven in part by the metacommunity concept (Holyoak et al. 2005; Logue et al. 2011), where a metacommunity is defined as a set of local communities linked by the dispersal of multiple interacting species (Leibold et al. 2004). Much attention has focused on the relative importance of environmentally and neutrally determined spatial effects on diversity and ecosystem function in metacommunities; however, it is increasingly recognized that these approaches do not incorporate sufficient complexity (Logue et al. 2011; Diniz-Filho et al. 2012). One issue is that most theoretical and empirical work on metacommunities has been spatially implicit (i.e., the spatial arrangement of local community patches is ignored) and aimed at process-based general synthesis. This contrasts with the field of landscape ecology, which centers on the generation and consequences of spatially explicit patterns (i.e., spatial 
arrangement is recorded), yet these patterns are often generated through idiosyncratic mechanisms that are not connected to general metacommunity theory.

Consequently, a synthesis of process-based metacommunity and pattern-based landscape ecology is much needed, considering that landscapes are the base template for metacommunity dynamics (Biswas \& Wagner 2012). There are at least two ways to achieve such a synthesis: 1) identify landscape features that are expected to generate particular metacommunity dynamics (Biswas \& Wagner 2012) and 2) identify situations in which specific spatially-explicit community patterns (the "community landscape") help identify underlying metacommunity dynamics. We focus on this second possible point of intersection because it has not been considered previously. We explore this possible link using a tropical twig-nesting ant community in a coffee growing landscape in southern Mexico. Ants are an ideal system because their colonies can be mapped, and taxon-specific spatial community assembly models already exist. These models are the ant mosaic hypothesis, whereby dominant ant species form mutually exclusive zones of colony expansion (Majer 1972; Leston 1978; Sanders et al. 2007), and the interstitial hypothesis, whereby subdominant ant species persist in "gaps" between the dominant species (Arnan et al. 2011). Previous work in our system indicates these two hypotheses could apply because there is strong interspecific aggression whereby dominant species remove subdominants from nest sites (Livingston \& Philpott 2010; Livingston et al. 2012). However, these hypotheses are likely overly simplistic (Sanders et al. 2007) and have not been considered in light of dispersal processes.

The two most common metacommunity models observed in natural systems are species sorting (matching between community composition and environment) and mass effects (a species sorting system with high dispersal creating source-sink dynamics) (Cottenie 2005). Previous work int he twig-nesting ant system has revealed the joint action of several metacommunity models: scale-dependent species sorting among common species in coffee across different intensities of coffee production and mass effects among rare species into the coffee plants from the shade trees where these rare species have larger colonies (Livingston et al. 2012). At a finer scale, spatial patterns in species co-occurrence have shown that the metapopulation dynamics of the most abundant species aggregate co-occurrence patterns in the rest of the community (Livingston \& Philpott 2010). However, co-occurrence patterns only reflect the frequencies of species-level pairings and are not spatially explicit patterns in entire communities.

Spatial clustering is a spatially explicit pattern referring to the nonrandom clumping of organisms across space (Haase 1995). It commonly results from dispersal processes coupled with local scale interactions. Here we test for spatial clustering within a twignesting ant community that inhabits coffee plants using nest location data from six sampling sites with resolution at the scale of single coffee plants. We partition the community into numerically dominant and subdominant ant communities, and perform a clustering analysis on each of these groups separately and on each of the component species separately. We hypothesize that the distribution of the dominant ant species community results from stochastic dispersal and colonization processes and is random, whereas subdominant ants will cluster into "gaps" between dominants (the interstitial hypothesis). At the species level, we hypothesize that individual dominant species will show clustering due to strong interspecific aggression (the ant mosaic hypothesis) whereas less aggressive subdominant species will not.

We then link these data to metacommunity models by relating our results to previous work on this community. Under mass effects, dispersal processes are expected to drive spatial pattern formation because populations require high dispersal rates to be self-sustaining. Under species sorting, local population growth is expected to drive spatial pattern formation because species are well adapted to local conditions. Consequently, we hypothesize that subdominant species may persist in interstitial zones under mass effects, with source populations in the shade trees, whereas dominant species are likely to sustain and expand colonies within the coffee plants following the ant mosaic hypothesis and species sorting. 


\section{MethodS}

Data for this analysis was collected in the Soconusco region of Chiapas, Mexico $\left(15^{\circ} 10^{\prime}\right.$ $\mathrm{N}$ and $92^{\circ} 20^{\circ} \mathrm{W}, 950-1220 \mathrm{~m}$ elevation, $\approx 4500$ $\mathrm{mm}$ rain annually) during 2009 . We surveyed ant community and location data from all coffee plants within six $400 \mathrm{~m}^{2}$ sites within Finca Irlanda, a commercial polyculture (Moguel \& Toledo 1999) and moderate shade farm relative to adjacent low and high shade farms (Livingston et al. 2012). Plant location was recorded using meter tape. Sites were selected in areas of the farm never previously sampled, on relatively level ground, with uniform coffee plant density, and not closer than $100 \mathrm{~m}$ to the edge of the farm or to an adjacent site. Environmental variables were also recorded, but we only use information on the distribution of available nest sites in our spatial analyses (i.e., the locations of coffee plants with at least one empty hollow twig). Nest site resources are a limited and limiting resource for the community (Philpott \& Foster 2005; Livingston \& Philpott 2010).

Survey sites contain an average of $54(\mathrm{SE}=9.35)$ plants each and are arranged in rows that are approximately 2 meters apart and with plants spaced by between 0.5 and 4 meters. Coffee plant surveys followed methodology detailed elsewhere (Philpott \& Foster 2005; Livingston \& Philpott 2010; Livingston et al. 2012) and generally involved removing and opening all dry twigs from each coffee plant within each site and recording the identity, presence and/or abundance of ants in occupied twigs. We considered any number of queens, workers, or alates of a species inside one or more twigs on a single coffee plant to constitute a colony (McGlynn et al. 2009), although colony limits likely extend across multiple plants in some cases (G Livingston, pers. obs.). Coffee plants typically contain one species, though they sometimes contain colonies from multiple species (Livingston \& Philpott 2010). A total of 1500 hollow twigs were encountered and 460 established ant colonies. Ants were identified using a photographic guide to the ants of the region and other published guides for neotropical ants (Fernandez 2003; Longino 2007).

Ripley's K was used to test for significant clustering of ant colonies at all possible spatial scales. To calculate Ripley's K, the number of other colonies in the neighborhood of each colony is compared with the number that would be expected if the colonies were randomly distributed on the coffee plants. The neighborhood is defined by a sampling circle, $t$, with a specified radius. To determine the degree of spatial clustering at different spatial scales, Ripley's $\mathrm{K}$ is calculated for a range of sampling circles up to a maximum radius equal to half the length of the shortest side of the plot (Haase 1995; Goreaud \& Pélissier 1999). Deviations from the random expectation indicate that the spatial pattern is either more clustered or more uniform than random, depending on whether the deviation is above or below the confidence interval range of the random expectation, respectively (Haase 1995; Goreaud \& Pélissier 1999).

For the clustering analysis, we classified species as dominant or subdominant based on the maximum colony size (number of nest-sites occupied on a single coffee plant). We consider maximum colony size as an indication of the specie's ability to aggressively expand colonies in coffee. Among the 13 species in our study, four species had a maximum colony size of nine nests, while the remainder all had three or less; we considered all species above nine as dominant and all those below three as subdominant. We excluded cases where a lone queen occupied a nest. Sites contained 7-10 species with 2-4 dominants per site. We believe this classification scheme has biological meaning for three reasons: 1) the occupancy rate of nest sites is high ( $82 \%$, Livingston et al. 2012) and most plants have only 1-3 nest sites (Livingston \& Philpott 2010). This means that species with maximum colony sizes greater than three are unlikely to occur by chance colonization events. 2) Although natural history information is limited for the species in this community, this method identifies three species as dominant (Pseudomyrmex simplex Smith, Pseudomyrmex PSW-53, and Myrmelachista mexicana Wheeler) that were previously found to show either positive or negative co-occurrence patterns with other species (Livingston \& Philpott 2010). These associations with other species together with their numerical dominance fit the criteria for identifying dominant species proposed by Majer et al. (1994). 3) Nest site take-overs have been observed in both the field and lab in this system among these dominants (Livingston \& Philpott 2010) and Pseudomyrmex and Myrmelachista congeners have been reported as dominants in other systems in Mexico (Gove \& Majer 2006; Kautz et al. 2012).

To test for the interstitial hypothesis, we calculated Ripley's K for dominants and subdominants (all species pooled) at each site. We estimated significance using 95\% confidence intervals based on 200 randomly generated colony distributions, i.e., a Monte Carlo approach constrained to plants that contained available nest sites. We further analyzed clustering of each species separately to look for evidence of the ant mosaic hypothesis. As an aid to interpreting clustering patterns, we compare three important variables between sites showing no clustering versus clustering: mean colony size for dominant species (correlated with aggression, (Majer et al. 1994)), mean nest site occupancy rate (indicating the strength of local nest site limitation, (Philpott \& Foster 2005)), and mean coffee plant size (height $x$ width, affecting the level of coffee plant interdigitation). One species, Procryptocerus hyleaus Kempf, is suspected to frequently disperse by moving whole colonies and not foundresses (G Livingston, pers. obs.), thus we removed it from this analysis. Simulations were conducted in MATLAB (Mathworks Inc., Natick, MA, USA) and all other analyses in R (R Development Core Team 2011). 


\section{RESUlTS}

As a group, dominant species never showed significant $(\mathrm{P}<0.05)$ clustering at any site; however, subdominant species showed significant clustering at two sites (both shown in Figure 1A). At the species level, significant $(\mathrm{P}<0.05)$ clustering at some spatial scales was observed in only $23 \%$ (12 of 53) of the analyzed species $\mathrm{x}$ site distributions (two representative cases shown in Figure 1B). Three of these significant results came from dominants and nine came from subdominants (Table 1). Subdominant species invariably showed clustering at small spatial scales because of limited spatial coverage, whereas dominant species showed clustering at a greater range of spatial scales (Figure 1B). The average sampling radius at which significant clustering was observed was $5.2 \mathrm{~m}(\mathrm{SE}=0.01)$ at the species level.

Mean colony size of dominant ant colonies was significantly larger in the two sites showing clustering $(2.39(\mathrm{SE}=0.19)$ versus $1.98(\mathrm{SE}=$ 0.1 ) nests per colony, $\mathrm{P}<0.05, \mathrm{~F}=4.4, \mathrm{~N}=330$, $\mathrm{df}=1$, ANOVA), but no significant differences were observed in occupancy rates or coffee plant size.

A
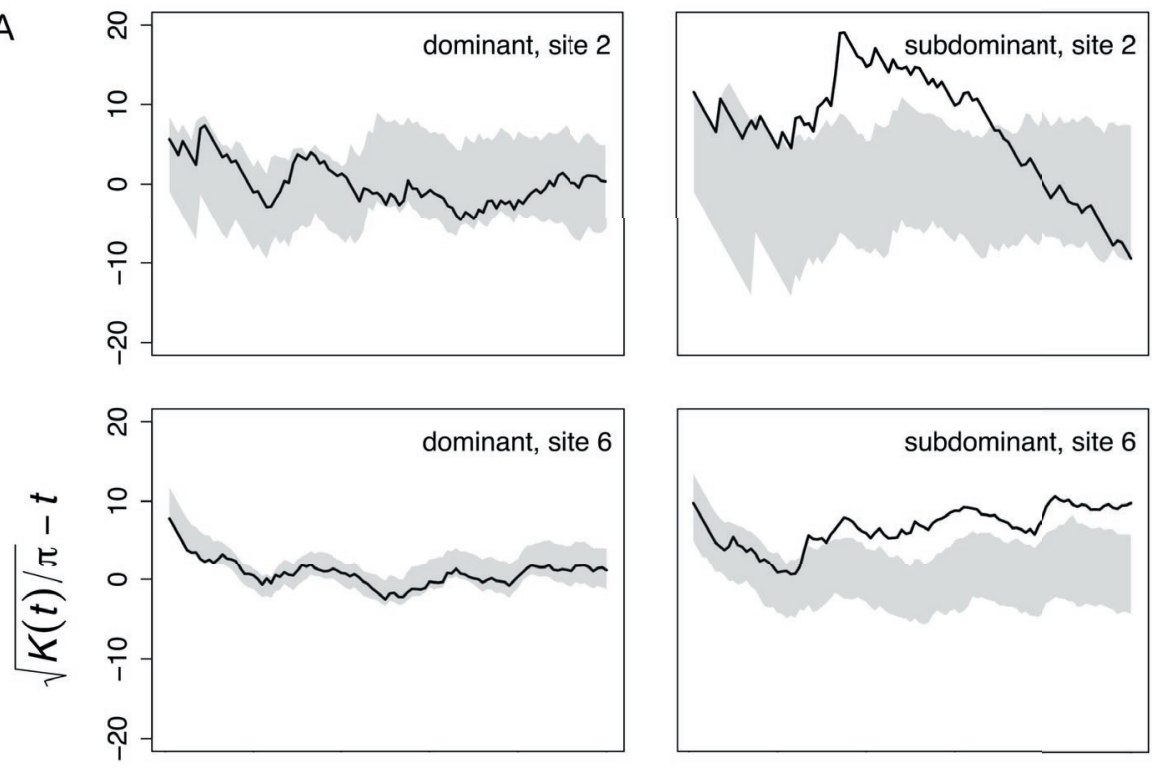

B

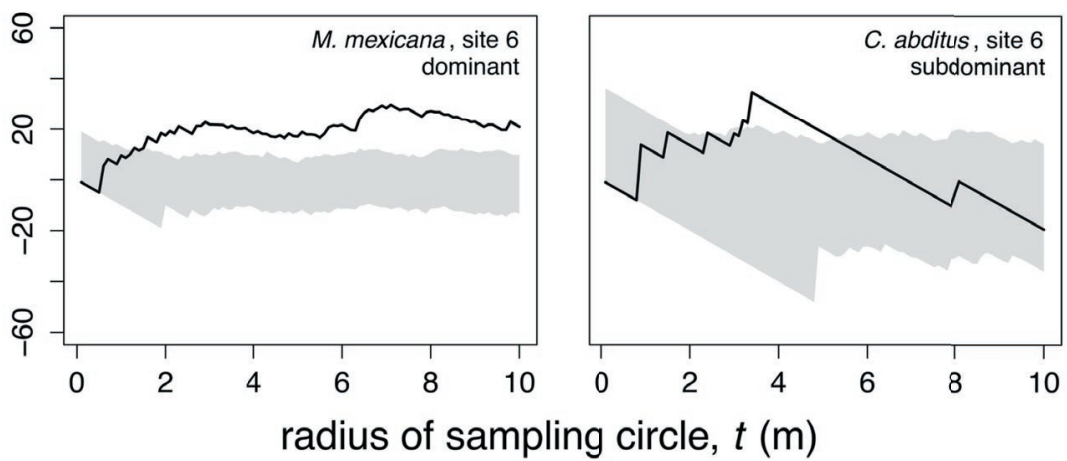

Figure 1. (A) Transformed Ripley's K output for dominant ants and subdominants at sites with significant clustering. The gray shaded areas show the $95 \%$ confidence intervals resulting from 200 random allocations of ant colonies to coffee plants. The black lines show the observed clustering of the ants in the field; observations that lie above the gray shaded area are significantly clustered at the indicated spatial scale, while observations below the shaded area are significantly uniform compared to the random expectation. (B) Transformed Ripley's K output for one representative dominant and one representative subdominant species showing significant clustering.

Figura 1. (A) Datos generados por el análisis de distancia multi-espacial Ripley K para hormigas dominantes y subdominantes en sitios con agrupamiento significativo. El área sombreada en gris muestra un $95 \%$ del intervalo de confianza como resultado de las 200 aleatorizaciones asignadas a las colonias de hormigas en las plantas de café. (B) Datos generados por el análisis de distancia multi-espacial Ripley K para una especie dominante y una subdominante mostrando agrupamiento significativo. 
Table 1. Abundance of colonies, lone queens and sites with significant clustering across species. All variables reported in the table are summed across all six sites.

Tabla 1. Abundancia de colonias, reinas solitarias, y sitios con agrupación significativa a través de los especies. Todas las variables corresponden a la suma total de los seis sitios.

\begin{tabular}{lcccc}
\hline Species & $\begin{array}{c}\text { Dominant abundance } \\
\text { (colonies) }\end{array}$ & $\begin{array}{c}\text { Subdominant } \\
\text { abundance (colonies) }\end{array}$ & Total lone queens & $\begin{array}{c}\text { No. sites with } \\
\text { significant clustering }\end{array}$ \\
\hline Camponotus \#1 & - & 13 & 0 & 1 \\
Camponotus abditus & - & 14 & 3 & 2 \\
Crematogaster \#1 & - & 3 & 0 & 0 \\
Crematogaster carinata & - & 2 & 1 & 0 \\
Myrmelachista \#1 & - & 12 & 6 & 0 \\
Myrmelachista mexicana & 16 & - & 0 & 1 \\
Nesomyrmex echinatindodus & - & 29 & 8 & 4 \\
Nesomyrmex pittieri & - & 2 & 0 & 0 \\
Procryptocerus hyleaus & - & 97 & - & 2 \\
Pseudomyrmex elongatus & - & 10 & 4 & 0 \\
Pseudomyrmex PSW-53 & 36 & - & 7 & 2 \\
Pseudomyrmex simplex & 99 & - & 7 & 0 \\
Pseudomyrmex ejectus & 113 & - & 16 & 0 \\
\hline
\end{tabular}

(-) indicates species not present

(-) indica especies no presentes

\section{DisCUSSION}

The significant clustering of the subdominant group in two of six sites and among $23 \%$ of the species $x$ site combinations provides mixed support for the interstitial and ant mosaic hypotheses. The interstitial hypothesis requires that aggression or resource competition between dominants and subdominants is sufficiently strong to force subdominants into interstitial zones. Although dominant and highly aggressive ant species occur in the shade tree canopy (e.g., Azteca sericeasur Longino Jackson et al. 2014) and nest site takeovers among twig-nesting species in coffee have been observed, overall patterns of co-occurrence among the twig-nesting community in coffee are random or aggregated (Livingston \& Philpott 2010). This suggests that aggressive interactions may not be sufficient to drive clustering of subdominants at all sites. The two sites that showed significant clustering for subdominants included the largest colonies of dominant species but did not differ in other characteristics. Thus, it is possible these two sites most closely approximate the larger colony sizes observed in the shade trees (Livingston et al. 2012) and larger colony size may enhance aggressive interactions among dominants and subdominants (Sagata \& Lester 2009).

The limited clustering at the species level and the fact that it occurs equally among dominant and subdominant species fails to support the ant mosaic hypothesis. Species commonly occur in isolation on single coffee plants in this system, but this pattern is likely due primarily to priority effects following dispersal and establishment (Livingston \& Philpott 2010) rather than aggressive interactions. At each of three sites, one dominant species showed spatial clustering. This suggests that dominant species are expanding their colonies via highly localized dispersal of foundresses, aggressive takeovers, or colony budding (Kautz et al. 2009). However, at the spatial scales we examined, spatially coherent expansion events are uncommon and do not generate a mutually exclusive mosaic among species. Ant mosaics produced by competition may be less common than previously thought because the literature suffers from a positive detection bias (Ribas \& Schoereder 2002). In addition, although many studies have found ant mosaics in tree crops (Ribas \& Schoereder 2002), our study is the first to examine its occurrence in an understory layer.

Previous experimental work indicates that the abundance of subdominant species may be more strongly regulated by dispersal than for dominants that may more frequently expand colonies into new nest sites after colony founding. Livingston et al. (2012) found that as a group rare species in the coffee layer (including e.g. Pseudomyrmex elongatus Mayr) likely represent sink populations that are supported by source populations in the shade 
trees, while abundant species (including e.g. Pseudomyrmex ejectus Smith and Pseudomyrmex simplex) respond to variation in environmental conditions and turnover in dominance across intra- and inter-farm scales.

Our interpretations are speculative with respect to process and require experimental confirmation. However, the pattern of occasional clustering of the subdominant community and no clustering among the dominant community indicates that links between landscape patterns and metacommunity models need further study. Subdominant clustering may be driven by dispersal from a source environment into "interstitial zones" where competition with dominant species is reduced. This couples community-level spatial clustering with a mass effects metacommunity model (Mouquet \& Loreau 2002) and the absence of clustering with species sorting. Future work should focus on other spatial patterns beyond clustering, such as bands, ribbons, labyrinths or stripes (Rietkerk \& van de Koppel 2008) and should examine to what extent dispersal coupled with localized species interactions in both homogeneous and heterogeneous metacommunites could play a role in their formation. As twig-nesting ants are a potential control agent of the coffee berry borer (Hypothenemus hampei Ferrari) and the coffee leaf miner (Leucoptera coffeella GuérinMèneville) (Larsen \& Philpott 2010; De la Mora et al. 2008), spatially explicit community patterns may translate into spatial variation in the provisioning of pest regulation services.

AcKNOWLeDGements: We thank U Perez Vasquez for field assistance and the Peters Family for allowing this work to be conducted on their farm. A de la Mora Rodriguez and two anonymous reviewers provided comments that greatly improved the manuscript. Funding was provided by the University of Texas at Austin (LLILAS and Department of Ecology, Evolution and Behavior) and the U.S. National Science Foundation (Grant number DEB-1020096 to S Philpott and DEB-0349388 to I Perfecto and J Vandermeer). G Livingston was supported by a US National Science Foundation Graduate Research Fellowship.

\section{REFERENCES}

Arnan, X; C Gaucherel \& AN Andersen. 2011. Dominance and species co-occurrence in highly diverse ant communities: a test of the interstitial hypothesis and discovery of a three-tiered competition cascade. Oecologia, 166:783-794.

BisWAS, S \& H WAGNER. 2012. Landscape contrast: a solution to hidden assumptions in the metacommunity concept? Landscape Ecol., 27:621-631.
Cottenie, K. 2005. Integrating environmental and spatial processes in ecological community dynamics. Ecol. Lett., 8:1175-1182.

Diniz-FILho, JAF; T Sigueira; AA Padial; TF Rangel; VL LANDEIRO; ET AL. 2012. Spatial autocorrelation analysis allows disentangling the balance between neutral and niche processes in metacommunities. Oikos, 121: 201-210.

FERNÁNDEZ, F. 2003. Introducción a las hormigas de la región Neotropical. Instituto de Investigación de Recursos Biológicos Alexander von Humboldt. Bogotá, Colombia.

Goreaud, F \& R PÉlissier. 1999. On explicit formulas of edge effect correction for Ripley's K-function. J.Veg. Sci., 10:433-438.

GOvE, AD, \& JD MAJER. 2006. Do isolated trees encourage arboreal ant foraging at ground-level? Quantification of ant activity and the influence of season, in Veracruz, Mexico.Agric. Ecosys. Environ., 113:272-276.

HAASE, P. 1995. Spatial pattern analysis in ecology based on Ripley's K-function: Introduction and methods of edge correction. J. Veg. Sci., 6:575-582.

Holyoak, M; MA Leibold \& RD Holt. 2005. Metacommunities: spatial dynamics and ecological communities. University of Chicago Press, USA.

Jackson, D; J Vandermeer; I Perfecto \& SM Philpott. 2014. Population responses to environmental change in a tropical ant: the interaction of spatial and temporal dynamics. PLoS ONE, 9:e97809

Kautz, S. 2009. Acacia-inhabiting Pseudomyrmex antsIntegrating physiological, behavioral, chemical and genetic data to understand the maintenance of ant-plant mutualisms. Ph.D. Thesis. Universität Duisburg-Essen, Germany.

Kautz, S; DJ Ballhorn; J Kroiss; SU Pauls \& CS Moreau. 2012. Host plant use by competing acacia-ants: mutualists monopolize while parasites share hosts. PloS ONE, 7:e37691.

LaRsen, A \& SM PhiLPOTt. 2010. Twig-nesting ants: the hidden predators of the coffee berry borer in Chiapas, Mexico. Biotropica, 42:342-347.

Leibold, M; M Holyoak; N Mouquet; P Amarasekare; JM ChASE; ET AL. 2004. The metacommunity concept: a framework for multi-scale community ecology. Ecol. Lett., 7:601-613.

Leston, D. 1978. A Neotropical ant mosaic. Ann. Entomol. Soc. Am.,71:649-653.

LiVINGSTON, GF \& SM PHILPOTT. 2010. A metacommmunity approach to co-occurrence patterns and the core-satellite hypothesis in a community of tropical arboreal ants. Ecol. Res., 25:1129-1140.

Livingston, G; SM Philpott \& A de la Mora Rodriguez. 2012. Do species sorting and mass effects drive assembly in tropical agroecological landscape mosaics? Biotropica, 45:10-17.

Logue, JB; N Mouquet; H Peter \& H Hillebrand. 2011. Empirical approaches to metacommunities: a review and comparison with theory. Trends Ecol. Evol., 26:482-491.

Longino, J. 2007. Ants of Costa Rica. Available at http:/ / academic.evergreen.edu/projects/ants / AntsofCostaRica.html (accessed 15 May 2009).

MAJER, JD. 1972. The ant mosaic in Ghana cocoa farms. Bull. Entomol. Res., 62:151-160.

MaJer, JD; JHC DelabIe \& MRB SMith. 1994. Arboreal ant community patterns in Brazilian cocoa farms. Biotropica, 
26:73-83.

McGlynN, TP; RM FaWCetT \& DA Clark. 2009. Litter biomass and nutrient determinants of ant density, nest size, and growth in a Costa Rican tropical wet forest. Biotropica, 41:234-240.

Moguel, P \& VM Toledo. 1999. Biodiversity conservation in traditional coffee systems of Mexico. Cons. Biol., 13: 11-21.

De la Mora, A; G Livingston \& SM Philpott. 2008. Arboreal ant abundance and leaf miner damage in coffee agroecosystems in Mexico. Biotropica, 40:742-746.

Mouquet, N \& M. Loreau. 2002. Coexistence in metacommunities: the regional similarity hypothesis. Am. Nat., 159:420-426.

Philpott, SM \& PF Foster. 2005. Nest-site limitation in coffee agroecosystems: artificial nests maintain diversity of arboreal ants. Ecol. Appl., 15:1478-1485.
R Development Core Team. 2011. R: A language and environment for statistical computing. R Foundation for Statistical Computing, Vienna, Austria. ISBN 3-90005107-0. Available at http://www.R-project.org/accessed 10 August 2012).

Ribas, CR \& JH Schoereder. 2002. Are all ant mosaics caused by competition? Oecologia, 131:606-611.

RietKerk, M \& J van De Koppel. 2008. Regular pattern formation in real ecosystems. Trends Ecol. Evol., 23: 169-175.

SAgAtA, K \& PJ Lester. 2009. Behavioural plasticity associated with propagule size, resources, and the invasion success of the Argentine ant Linepithema humile. J. Appl. Ecol., 46:19-27.

SANDERS, NJ; GM CRUTSINGER; RR DUNN; JD MAJER \& JHC Delabie. 2007. An ant mosaic revisited: dominant ant species disassemble arboreal ant communities but cooccur randomly. Biotropica, 39:422-427. 